\title{
Shooting may aggravate rather than alleviate conflicts between migratory geese and agriculture
}

\author{
Silke Bauer ${ }^{1,2}$ (D) | Simeon Lisovski ${ }^{2}$ (i) | Ramona J. F. M. Eikelenboom-Kil ${ }^{1,3}$ | \\ Mitra Shariati $^{4}$ | Bart A. Nolet ${ }^{1,5}$
}

${ }^{1}$ Department of Animal Ecology, Netherlands Institute of Ecology (NIOO-KNAW),

Wageningen, The Netherlands

${ }^{2}$ Department of Bird Migration, Swiss Ornithological Institute, Sempach, Switzerland

${ }^{3}$ Resource Ecology Group, Wageningen University, Wageningen, The Netherlands

${ }^{4}$ Faculty of Geo-Information Science and Earth Observation (ITC), University of

Twente, Enschede, The Netherlands

${ }^{5}$ Theoretical and Computational Ecology, IBED, University of Amsterdam, Amsterdam, The Netherlands

\section{Correspondence}

Silke Bauer

Email: silke.s.bauer@gmail.com

Funding information

Faunafonds

Handling Editor: Des Thompson

\section{Abstract}

1. Many migratory goose populations have thrived over the past decades and their reliance on agricultural resources has often led to conflicts. Control and management measures are sought after but since migratory geese use several sites in their annual cycle, local management actions should consider their potential effects further down the flyway.

2. We used a behaviour-based migration model to illustrate the consequences of management actions involving hunting, derogation shooting and scaring at single or multiple locations along the flyway, considering various mechanisms of how geese might perceive shooting/hunting. Furthermore, as a proxy for the agricultural damage caused, we calculated the per capita biomass consumption between scenarios-both over time and cumulatively.

3. We found that hunting, shooting and scaring can result in a suite of direct and indirect consequences on migration and foraging behaviour. Most importantly, hunting/shooting on a particular site had implications not only for the behaviour at the actual site but also for behaviour at, and use of, other sites. Furthermore, the specific consequences of shooting/hunting could be counter-intuitive, that is, aggravate rather than alleviate agricultural damage, depending on where along the migration route changes had taken place and the mechanisms through which hunting/shooting was assumed to affect geese.

4. Synthesis and applications. Management plans are being discussed or implemented for several migratory goose populations and often include shooting, hunting or scaring at one or multiple locations. Using a behaviour-based model, we assessed the consequences of such local management measures and found that they can indeed lead to a reduction of agricultural conflicts locally but may also aggravate the conflict or shift it to other sites along the flyway. Thus, we recommend the use of these models to scrutinize the efficiency of specific management measures and to assist in identifying an international management regime that minimizes conflicts on a flyway level while still maintaining migratory populations.

\section{KEYWORDS}

agricultural damage, conflict, flyway management, geese, hunting, migration, shooting, stopover site use 


\section{1 | INTRODUCTION}

The populations of many migratory goose species have thrived over the past decades. They have also become increasingly reliant on agricultural resources, particularly during the non-breeding season, and thus, have frequently raised conflicts with agriculture (e.g., Fox, Elmberg, Tombre, \& Hessel, 2017; Jensen, Wisz, \& Madsen, 2008; MacMillan \& Leader-Williams, 2008; Tombre, Eythórsson, Madsen, Madsen, \& Piersma, 2013). For instance, the agricultural damage that the population of white-fronted geese (Anser albifrons) caused in the Netherlands has been roughly estimated to amount between 2.5 and 4.5 Million Euro per winter season (in the period 2005-2012), which is almost 7 Euro per goose (Jongejans, Nolet, Schekkerman, Koffijberg, \& de Kroon, 2015)but, obviously, there is great variation among regions, crop-types and years.

Within the suite of potential management options, hunting, scaring and/or derogation shooting are often among the prime candidates. Shooting and hunting were mainly employed to control the sizes of the so-called overabundant populations-with mixed success though. For instance, lesser snow goose (Anser caerulescens) escaped density-dependent reproduction by colonizing new breeding grounds, and by now, might be too abundant to effectively control (Koons, Rockwell, \& Aubry, 2014). In the case of its also over-abundant sister species, greater snow goose (Anser caerulescens atlantica), hunting during spring migration reduced recruitment (Morrissette, Bêty, Gauthier, Reed, \& Lefebvre, 2010), and management measures, although not fully successful, have stabilized the population (Lefebvre et al., 2017).

In addition to direct and immediate lethal effects, hunting, shooting, and scaring may also have indirect, distant and delayed consequences as they alter the migration and foraging behaviour of geese (Juillet, Choquet, Gauthier, Lefebvre, \& Pradel, 2012; Klaassen, Bauer, Madsen, \& Possingham, 2008; Klaassen, Bauer, Madsen, \& Tombre, 2006; Figure 1). The geese probably respond to such human-induced "artificial", or perceived, mortality risks in a similar way as they would respond to natural predation risk. However, irrespective of whether mortality risks originate from natural or humaninduced sources, it is typically unknown in which way and for how long these risks alter the behaviour of geese; to what extent local actions elicit undesired compensation behaviours at other sites and thus, whether they ultimately alleviate, or rather aggravate, agricultural damage. Ultimately, we need to identify management measures that allow a trade-off between reducing agricultural conflicts while still sustaining migratory wildlife populations as an internationally shared objective, for example, in the Convention on Migratory Species (http://www.cms.int/) and the African-Eurasian Waterbird Agreement (http://www.unep-aewa.org/).

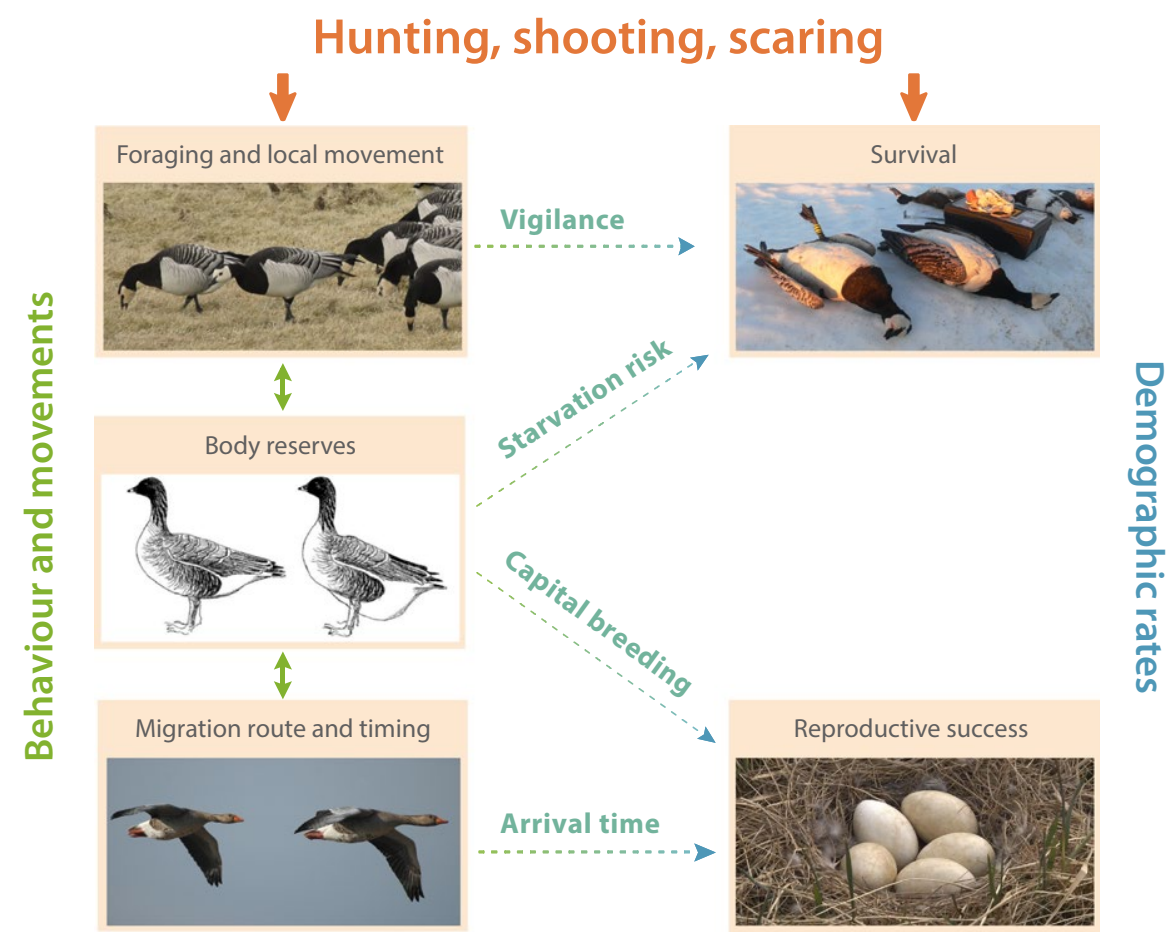

FIGURE 1 Schematic overview of direct and indirect effects of shooting, scaring and disturbances on foraging and migration behaviour and ultimately on demographic rates of migratory waterfowl populations. Obviously, hunting can directly reduce survival if birds are shot but also indirectly, if it alters the trade-off between foraging and vigilance. More time spent vigilant reduces foraging time (or intensity) and thus also the time required to accumulate body reserves for migration. Graphical material (from top-left to down-right): Barnacle geese (Branta leucopsis) foraging in the Netherlands (c) Hugh Jansman, abdominal profiles of pink-footed geese (Anser brachyrhynchus) modified after Madsen and Klaassen (2006), flying greylag geese (Anser anser) @ Hugh Jansman, barnacle geese shot in Nenetskii Okrug, Russia ( Bart Nolet, nest of white-fronted geese 
We used a theoretical approach-a state-dependent optimal migration model-to assess the consequences of derogation shooting, hunting and scaring on the migration behaviour and demographic rates of geese, and how these accumulate in agricultural damage. We exemplarily apply our model to the Baltic-North Sea population of whitefronted geese. This population increased from 10,000 to 50,000 in the 1950s to 1,200,000 around 2010 (Fox et al., 2010; Mooij, Faragó, \& Kirby, 1999), raising serious conflicts with agriculture, particularly in the Netherlands where the large majority of these geese overwinter. Consequently, a new goose management regime has been set up in the Netherlands, which includes the creation of accommodation areas where geese can forage undisturbed, while in agricultural areas scaring (including shooting) has been allowed to chase geese away (Kwak, Van der Jeugd, \& Ebbinge, 2008). As a result, a considerable proportion of the wintering white-fronted geese is again being shot (e.g. $5 \%$ in 2007/08; Jongejans et al., 2015). In addition to derogation shooting in the Netherlands, geese are also hunted further along the flyway in Russia with hunting bags estimated to be around 100,000 (Mooij et al., 1999). As the Netherlands has recognized its international responsibility in sustaining the population of wintering white-fronted geese, the renewed permission of shooting raised the question in how far this objective would be undermined. Shooting may cause additional mortality to the geese (Menu, Gauthier, \& Reed, 2002), but it may also change migration and foraging behaviour (Jonker, Eichhorn, van Langevelde, \& Bauer, 2010). We were particularly interested in the interplay of shooting at multiple locations and its efficacy in containing agricultural damage across the flyway.

While shooting poses a real mortality risk, scaring and other sources of human disturbance are usually not lethal but can still be perceived as life-threatening and lead to behavioural adjustments. There is a variety of potential responses to the perceived threats of shooting and scaring (Figure 1): For instance, geese may increase vigilance at the expense of foraging duration or intensity, and thus, take longer before they accumulate the body reserves required for migration. Alternatively, geese might depart from a site earlier with lower-than-required body reserves, jeopardizing survival during migration and/or reproductive success (Béchet, Giroux, \& Gauthier, 2004). Geese might also respond to the perceived predation risk with escape behaviours, mainly flights, which increase daily energy expenditure and, in turn, lead to compensatory foraging (Nolet, Kölzsch, Elderenbosch, \& van Noordwijk, 2016). Thus, the agricultural damage expected at specific sites depends on whether foraging is intensified to compensate for the additional energy expenditure from escape behaviours, or reduced with increased vigilance, whether all or some of the above change the timing of migration (departure from The Netherlands and staging times), the choice of stopover sites and the route taken (avoidance of risky sites).

\section{2 | MATERIALS AND METHODS}

\section{1 | Outline of model essentials}

We developed a state-dependent dynamic optimization model to calculate the migratory decisions that maximize the fitness of a female white-fronted goose. Here, we briefly outline fundamental and relevant model characteristics to reduce redundancy to earlier publications, using a similar model (e.g. Bauer, Ens, \& Klaassen, 2010; Bauer, Van Dinther, Høgda, Klaassen, \& Madsen, 2008; Weber, Ens, $\&$ Houston, 1998) but provide a full model description and parameterization in Appendix S1.

The model covered the spring migration of a female goose to the breeding grounds. The migration period was divided into whole days, and preparation for spring migration was assumed to start in the Netherlands from 1 March onwards. We consider a flyway with the wintering region in the Netherlands (NL), stop-over regions in Germany (D), Poland (PL), Lithuania/Ukraine (Lit/Ukr), Estonia/Tver (Est/Tver), Leningrad Oblast/Karelia/Kostroma (Kar/Kos), Arkhangelsk Oblast/Komi (Ark), Nenetskii Okrug (Nen) and the breeding grounds in Kolguev (Figure 1). These regions were identified from spring migration tracks of 16 individuals in an earlier study (for details see http:// www.blessgans.de (van Wijk et al., 2012)), and we amalgamated individual stop-over locations with similar spring phenology into stop-over regions (see Appendix S2). We characterized all regions by their onset of spring, metabolisable energy intake (MEI) and predation risk (see Table S1 in Appendix S1). The onsets of spring were determined from the date when spring temperatures increased most steeply (van Wijk et al., 2012), but shifted these c. 4 weeks earlier throughout all sites knowing that food was available in the wintering grounds at the starting date of the model. MEI depends on quality and quantity of food available but also on foraging intensity and day length and thus, generally increases northwards in spring. In modelling terms, MEI values indicate the highest possible fuelling rates. As no empirical MEI-values were available for our (sub-)population, we estimated them from empirical observations of abdominal profiles and their observed changes at stop-over sites from the Greenland-breeding population of whitefronted geese (Fox, Glahder, \& Walsh, 2003).

A model-bird was characterized by body reserves and location at a particular day. Body reserves, $x$, could vary between 0 , when the bird reached a minimum body mass and was assumed to die of starvation and $x_{\max }=100$ where the maximum fuel load was reached. For White-fronted geese, minimum and maximum body mass are 1.5 and $2.5 \mathrm{~kg}$, respectively, and given an energy content of fuel of 29,000 J/g (Madsen \& Klaassen, 2006), the energy equivalent of $x_{\max }$ is $29,000 \mathrm{~kJ}$.

Within each time-step, a bird could choose between remaining and foraging on its present site or migrating to one of the next sites. Decisions depended on body stores, time of the year and expected conditions on present and subsequent sites. We calculated the optimal, that is, fitness-maximizing, decisions, which included trade-offs between gaining energy and avoiding predation, and also weighed the benefits (or costs) of being closer to the breeding grounds against the benefits (or costs) of staying at the present site (for details on how optimal decisions are calculated, see Appendix S1).

\subsection{1 | Stay and forage}

If staying on the present site, a bird requires energy, $e$, for maintaining its metabolism and may choose to forage with intensity $u$. If gain 
from foraging exceeds expenditure, the bird increases, and otherwise depletes, its energy reserves. Foraging intensity $u(0 \leq u \leq 1)$ is the fraction of the maximum gain $G$ at a site that a bird can deposit (provided $x \leq x_{\max }$ ). Since there might be stochastic differences in individual foraging success, we modelled the gain rate at site $i$ as a discrete random variable with outcomes $g_{1}(i), \ldots g_{j}(i), \ldots, g_{\max }(i)$ and the probability of achieving a particular gain is given by

$$
P\left\lfloor G=g_{j}(i)\right\rfloor=p_{j}(i) \text {, where } \sum_{j} p_{j}(i)=1 \text {. }
$$

Stochastic differences in foraging success imply that a bird might experience (series of) "bad luck" in foraging, which elevate starvation risk when reserves are insufficient. Therefore, accounting for such stochasticity will often yield a higher "best" foraging intensity (see below) than under deterministic foraging success. Consequently, if a bird with body reserves $x$ forages with intensity $u$ at site $i$, its body reserves in the next time-step will be $x+u g_{j}(i)-e$, with the energy expenditure $e$ being $1160 \mathrm{~kJ} / \mathrm{d}$ (Baveco, Kuipers, \& Nolet, 2011).

\subsection{2 | Predation risk}

Maintaining fuel stores and foraging incur fitness costs in terms of increased risk of predation or injury (Witter \& Cuthill, 1993). We assume that the overall "predation" risk $m(x, u, i)$ depends on a constant background predation risk, $m_{0}=10^{-4}$, but also on the level of body reserves $x$, and on foraging intensity $u$ :

$$
m(x, u, i)=m_{0}(i)+b_{1}(i) \frac{\left(x+u g_{j}(i)\right)^{a_{1}+1}-x^{a_{1}+1}}{\left(a_{1}+1\right) u g_{j}(i)} \cdot b_{2}(i) u^{a_{2}}
$$

with background predation risk $m_{0}=10^{-4}$, mass-dependent coefficient $b_{1}=10^{-3}$, foraging-intensity-dependent coefficient $b_{2}=10^{-4}$ and $a_{1}$ and $a_{2}$ the mass- and foraging-dependent exponents, which were set to 2 (Madsen, Frederiksen, \& Ganter, 2002), foraging intensity $u$ and stochastic gain $g_{j}(i)$ at site $i$. Although the coefficients are chosen such that typically $m(x, u, i) \ll 1$ (see Figure S2 in Appendix S1), we constrain $0 \leq m(x, u, i) \leq 1$, and $m(x, u, i)=m_{0}(i)$ for $u=0$. Please note that predation risk is not fixed per se but, rather, used to specify the costs of behaviours and the costs of being in a specific state. Implicitly, we assume that a higher foraging intensity reduces vigilance and carrying body stores reduces manoeuvrability and/or escape behaviour, and that the first has a stronger effect on predation risk than the latter. Birds can respond to these risks by adjusting behaviour, for example, increasing vigilance or keeping body stores at a lower level, and thus, minimize mortality. We employ an optimization procedure to evaluate these costs and benefits for the animal's current state (i.e. its body reserves and location) and identify the trade-off, that is, the best $u$, between avoiding starvation and predation, and gaining energy.

Alternatively, a bird may decide to migrate to a following or a preceding site given its body reserves permit to cover the distance to the destination site. If an individual decides to depart, it should fly to the site yielding the maximum expected fitness at the destination (for details on flight range and calculation of optimal target site, see Appendix S1).
Once the bird has reached the breeding grounds, its expected reproductive success is determined by time of arrival and body reserves at arrival assuming that successful breeding is only possible if birds arrive within a rather short time-window (e.g. Bêty, Giroux, \& Gauthier, 2004; Madsen et al., 2007) and that reproductive output is also related to the amount of reserves ("capital breeding", for review see Stephens, Boyd, McNamara, \& Houston, 2009). We set the arrival-window between 26 May and 8 June, based on the arrival dates of 16 tracked white-fronted geese and their inferred later breeding status (van Wijk et al., 2012, Appendix S2) and used a sigmoidal relation between body reserves upon arrival and expected number of young. When birds failed to reach the breeding grounds within this time-window or with insufficient body reserves, they cannot reproduce in the present year but may do so in subsequent year(s). Expected fitness gains from future breeding attempts depend on survival and future reproductive successboth of which are rather high in long-lived species (for details, see Appendix S1).

\section{2 | Scenarios}

As we were particularly interested in the consequences of scaring and shooting, we run scenarios with changes in the predationrisk parameters that reflect the (perceived) mortality risk of such human activities. To this end, we increased background predation risk $m_{0}$ as well as predation risk coefficients $b_{1}$ and $b_{2}$ (see Equation 1) independently and in combination, in steps of factor 10 from their default values, that is, $m_{0}=10^{-4}$ (standard setting) to $10^{-3}$ and $10^{-2}, b_{1}=10^{-3}$ to $10^{-2}$ and $10^{-1}$; and $b_{2}=10^{-4}$ to $10^{-3}$ and $10^{-2}$.

Alternatively, scaring and shooting can lead to frequent escape flights and thus, higher daily energy expenditure. Therefore, we tested the consequences of increasing daily energy expenditure by $5 \%$ and $10 \%$ (Nolet et al., 2016).

Furthermore, as we aimed at identifying the consequences of scaring and shooting on one or several sites along the flyway, we run the above scenarios both in one site alone and combined in two and three sites. We focused particularly on NL, Est/Tver and Nen as these are the sites where, in reality, either hunting pressure is high or derogation shooting has been introduced.

For all scenarios, we analysed model predictions with regard to individual choice of stop-over sites, migration timing and body reserve dynamics. As an indication of the maximum agricultural damage potentially caused by the geese' foraging, we recorded individual consumption per site.

\section{3 | RESULTS}

\subsection{Stopover site use and staging times}

Under the standard parameter setting, geese were predicted to depart from the Netherlands at the end of March and to use primarily Est/Tver and Nen on their way to the breeding grounds. All other 
(a)

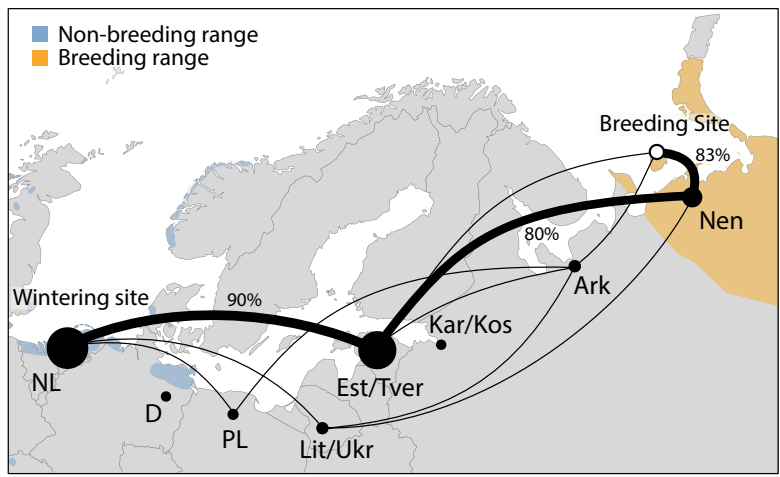

Increased predation risk in NL

FIGURE 2 (a) Migration route of white-fronted geese from the wintering region in NL, via stop-over regions in Germany (D), Poland (PL), Lithuania/ Ukraine (Lit/Ukr), Estonia/Tver (Est/Tver), Leningrad Oblast/Karelia/Kostroma (Kar/ Kos), Arkhangelsk Oblast/Komi (Ark), Nenetskii Okrug (Nen) to their breeding grounds in the Kolguev region. Under the standard parameter setting, geese would mainly use NL, Est/Tver and Nen (staging time indicated by circle size) but there was also considerable variability in the use of sites and staging times. Increasing hunting/shooting intensity (here by increasing all three parameters $m_{0}, b_{1}$ and $b_{2}$ by factor 10 "+" and $10^{2}$ "++") changed departure and staging times as well as mortality but the specific consequences depended on where predation risk was changed and how much. The predicted consequences for mean migration patterns (left panel) and mortality (right panel) are shown for changes in (b) NL (arrows indicate the changes compared to the migration patterns under the standard parameter setting), (c) Est/Tver, (d) Nen alone and when they occur in all three of these sites (e). For NL, "Days at site" are days after 1 March

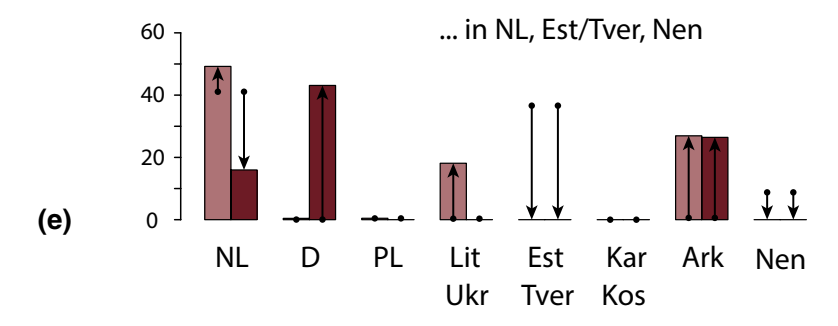

(d) (b)
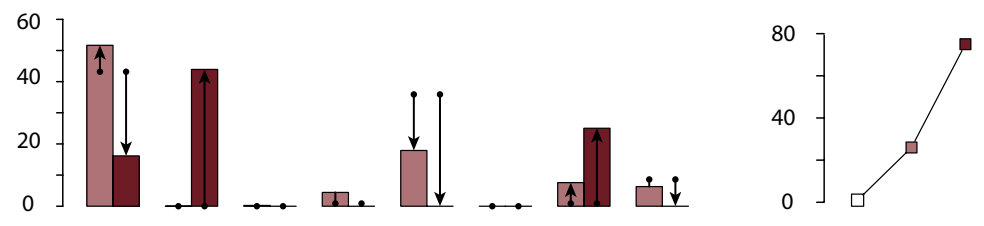

(c)
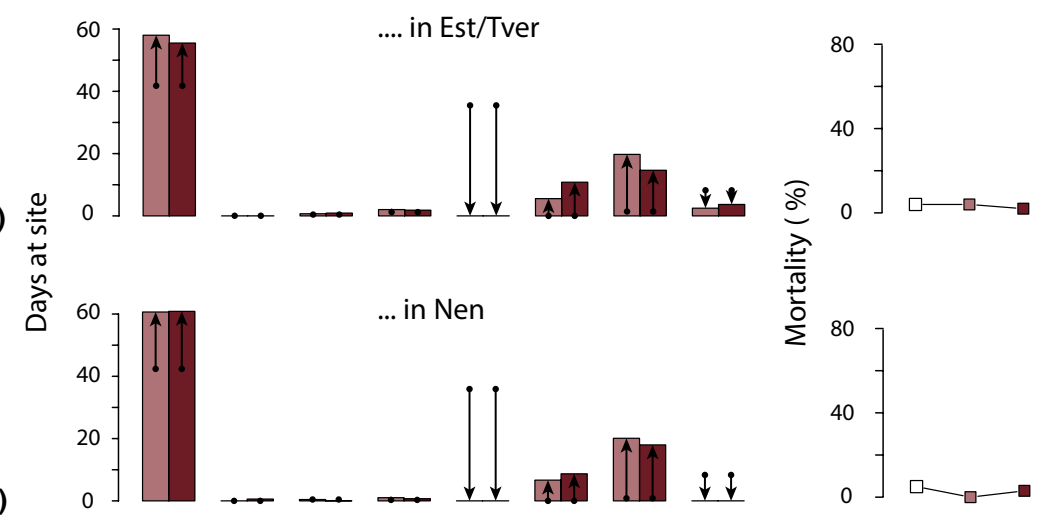

(e)

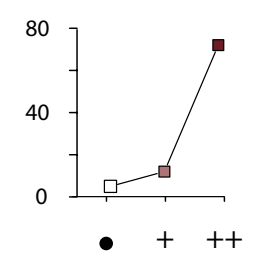

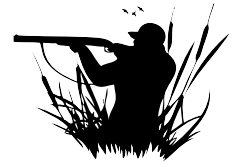

Hunting or shooting intensity

- Standard

$+$ sites were used for a few days at most; yet, there was considerable variation in how individuals migrated, which sites they used and for how long they stayed (Figure 2a).

When predation risk was changed only at the wintering site (NL), this altered the departure from NL and the geese' staging times elsewhere (Figure 2b). Counter-intuitively, a higher-than-standard predation risk delayed departure from NL, decreased staging time in Est/Tver and increased staging time in Ark with little changes elsewhere. Only under the highest predation risk in NL did geese depart earlier from NL and stayed in $D$ instead, largely skipped Est/Tver and used Ark for more than 3 weeks. This general pattern also arose when the three predation risk parameters were changed independently, albeit increases in foraging-intensity-dependent predation risk $\left(b_{2}\right)$ had the strongest consequences for departure (not shown).

If predation risk was changed in either the central (Est/Tver) or northern (Nen) site, staging times changed on the site with higher predation risk but also carried over to the use of other sites. With higher risks in Est/Tver, geese reduced their staging here, ultimately skipped this site and stayed considerably longer in NL, Kar/Kos and Ark (and slightly longer in PI, Lit/Ukr) (Figure 2c). A similar pattern emerged for changes in Nen, which was also sidestepped under high predation risk and instead, geese stayed longer in NL, Kar/Kos and Ark (Figure 2d). In contrast, changing predation risk in Kar/Kos or Ark hardly changed staging times-possibly because they were the least-preferred sites in the standard setting. 
Under simultaneous changes in predation risk at wintering $(\mathrm{NL})$, central (Est/Tver) and northern (Nen) sites, geese largely avoided all of these and instead, mainly used D, Lit/Ukr and Ark (Figure 2e).

Changes in daily energy expenditure as consequence of frequent escape behaviours had no major influence on migration patterns. The only non-negligible influence was a higher expenditure in NL which led to somewhat later departures from NL and the additional use of Lit/Ukr as stop-over. A higher expenditure on any of the other sites had no influence on migration-likely because their higher MEIvalues facilitated a compensation for the additional expenditure.

\section{2 | Fitness consequences}

Mortality was generally very low in the standard setting (c. 5\%). A higher predation risk anywhere along the migration route obviously increased mortality (right panel in Figure 2); however, how much mortality increased depended on where predation risk was changed and which parameter of predation risk. Obviously, mortality increased most (to $>70 \%$ ) when all three predation risk parameters $\left(m_{0}, b_{1}\right.$ and $\left.b_{2}\right)$ were affected, and less when only one of these parameters changed: for changes in $b_{1}$ the highest observed mortality was $19 \%$; for changes in $b_{2}$ the highest observed mortality was $17 \%$, and for changes in background predation risk $m_{0}$ mortality was $27 \%$. Furthermore, while a higher risk in NL or Nen increased mortality substantially, a higher predation risk on any of the other sites had not such drastic consequences-for these changes, mortality remained relatively low, indicating that reducing foraging intensity, or avoiding risky sites and substituting them by one of the (safer) sites could effectively alleviate the higher risk.

Changing energy expenditure had no major influence on mortality-it largely remained at a low level, with the minor exception of higher expenditure in NL, which slightly increased mortality.

\section{3 | Consumption}

Agricultural damage results primarily from the foraging activities of geese and therefore, we used biomass consumption per site as a proxy for the damage expected at each site. The overall pattern of biomass consumption across the flyway clearly reflects the preferences of geese for specific sites, their staging times there but also the importance of fuelling at these sites. In the standard scenario, the preferred sites were NL, Est/Tver and Nen, where the geese either prepared for a long migratory leg (NL and Est/Tver) or for breeding (Nen), and consequently, we found the highest biomass consumption on these sites (Figure 3).

As changes in predation risk altered the use of sites and shifted their importance (see above), the expected damage to local agriculture changed likewise. For instance, a higher predation risk in NL increased biomass consumption in NL considerably (Figure 3) and decreased it only under the highest predation risk with its much higher mortality. Also when predation risk in one of the other sites was increased, geese stayed and foraged longer in NL.

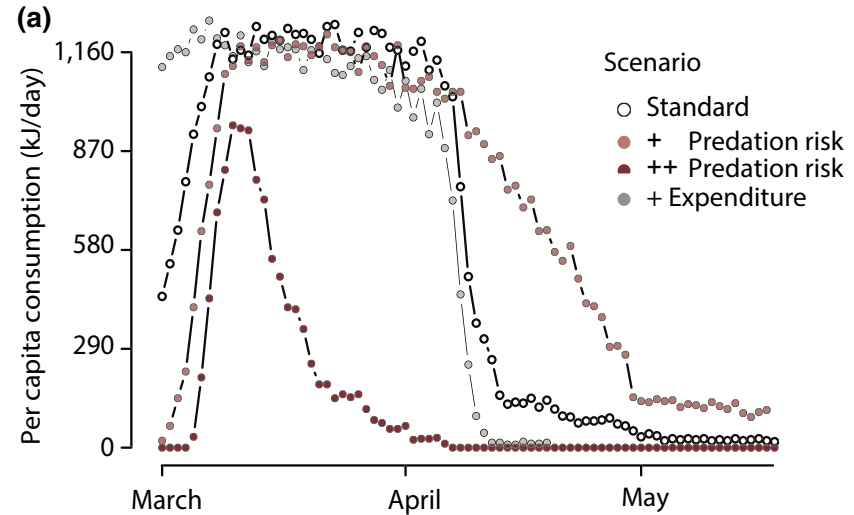

(b)

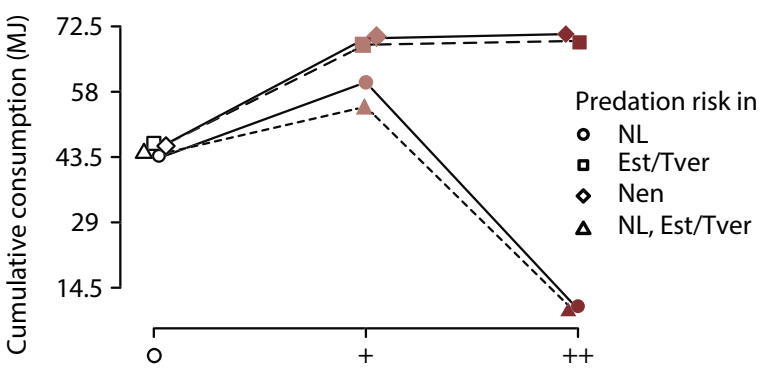

FIGURE 3 Biomass consumption in the main wintering site (The Netherlands, NL) under increasing levels of shooting/hunting intensity, which may increase predation risk ("+" and "++" Predation risk, see Figure 2) and/or energy expenditure ("+ Expenditure" resulting from $10 \%$ higher expenditure) in NL, Est/Tver and Nen. (a) Per capita daily biomass consumption (averaged over starting population of 100 individuals) over the entire spring migration period increased with higher predation risk $(O)$ as geese left slower and later but dropped sharply as predation risk increased even further (O) while increasing daily energy expenditure had only a minor effect. Consequently, the biomass consumed per goose in $\mathrm{NL}$ over the entire season (b) increased with higher predation risk in NL but also with higher predation risk in either Est/Tver, Nen or in all of these sites but consumption in NL dropped when predation risk increased further in NL or in all sites combined

\section{4 | DISCUSSION}

Migratory animals link distant sites (Bauer \& Hoye, 2014) and this also applies to the consequences of management actions (Hessen, Tombre, van Geest, \& Alfsnes, 2017). Changing conditions on a particular site-be it through management or natural processes-not only alters the behaviour of migrants immediately and locally but could do so also at a later time and at a distance. This is also the case in our study, where (1) shooting/hunting influenced the use of focal sites but also that of other sites, sometimes leading to counter-intuitive consequences. Furthermore, our results suggest that the consequences of shooting not only vary with its intensity but (2) also depend on which sites were affected and (3) on the mechanisms through which it is assumed to influence birds.

\subsection{Consequences on focal sites and beyond}

Increasing shooting intensity in the wintering site $(\mathrm{NL})$ first delayed spring departure and only advanced it under even higher intensities. A 
longer stay may appear counter-intuitive but results from the reduced foraging intensity (and the higher vigilance) with which geese attempt to alleviate the higher predation risk. Consequently, the geese then needed to forage longer to reach the level of body reserves required for the next migratory leg. However, when shooting intensity increased further, a lower foraging intensity does not sufficiently reduce mortality risk and then, geese minimized time on, or completely avoided, high-risk sites, staying on less risky sites further along the flyway instead. Avoidance of risky sites also explains why geese stay longer in NL when hunting intensity in central or northern sites was increased. Such changes in time spent on sites, skipping of site or use of alternative sites when (perceived) mortality risk is high have also been observed in other studies: Western sandpipers have altered migration routes as raptor populations have recovered and increased predation risk (Ydenberg, Butler, Lank, Smith, \& Ireland, 2004), pinkfooted geese changed staging times with scaring activities on staging sites (Klaassen et al., 2006) or Jonker et al., (2010) suggest increased predation risk as a likely reason for Barnacle geese (Branta leucopsis) delaying their departure from their wintering site (NL).

Obviously, the redistribution of geese along the flyway and the use of alternative sites depend on availability of sites along a flyway. In spring, sites towards the Arctic become only successively available with the retreating ice front and the local onset of spring (Nuijten et al., 2014). Global climatic changes may alter timing and speed of the onset of spring; yet, these changes are uneven across sites and are generally predicted to be stronger/accelerated in the Arctic (Stocker et al., 2013). If the trend towards earlier springs in Central Europe continues and Germany and possibly Poland become available earlier, geese might indeed be forced out of the Netherlands with an intensified scaring and shooting regime. Such shifts in the winter distribution with rising winter temperatures in Europe have already been observed in several waterfowl species, (Lehikoinen et al., 2013; Ramo et al., 2015).

\subsection{Consequences vary dependent on which sites affected}

The patterns in demographic rates as a consequence of shooting are also diverse. Survival can drop considerably under high shooting intensity but also remain high if only one site is affected, provided that this site is not the wintering or last stopover site before reaching the breeding grounds, or if the increase in risk is moderate only. In these cases, geese can adjust behaviour or use alternative site(s). However, if a combination of sites is affected or either the starting and last stopover site (NL and Nen) have a high predation risk, survival dropped considerably.

\section{3 | Mechanism through which hunting/shooting affects geese}

As our results have shown, scaring and shooting can have various consequences depending on which causal (mechanistic) pathway we assumed. We changed energy expenditure and three aspects of predation risk, assuming that either background mortality increases with shooting, that predation risk increases with intense foraging or with higher body reserves (Guillemain, Elmberg, Arzel, Johnson, \& Simon, 2008), or that daily maintenance costs are increased with frequent escape flights (Nolet et al., 2016). All of these possible responses have been shown in reality (but not necessarily in combination or in the same species): For instance, if disturbed by hunting, snow geese flew off repeatedly, interrupted feeding and gained less energy than undisturbed geese (Béchet et al., 2004). Birds may also enhance vigilance (Pomeroy, Butler, \& Ydenberg, 2006), engage in specific escape behaviours (Béchet et al., 2004; Riddington, Hassall, Lane, Turner, \& Walters, 1996) or departure earlier from, or avoid, regions with higher mortality risk (Morris et al., 2008), all of which may have consequences for the redistribution along flyways. If detailed predictions of specific management actions are sought, we need to identify how particular species will perceive such management and what their primary and knock-on responses will be.

There are some abstractions inherent to our modelling approach that might be specifically targeted in future applications: First, our approach represents space (within stop-over sites) only implicitly, that is, we did not consider small-scale characteristics of sites such as areas of suitable habitat or carrying capacities that likely differ between regions and change competition between individual geese. Second, we assumed that geese are "informed migrants", that is, they "knew" conditions in all regions along the migration route and respond optimally to them. Although this might appear a strong assumption, several goose species have demonstrated a high capacity of swiftly responding to new conditions and adopting new migration patterns (Clausen, Madsen, Cottaar, Kuijken, \& Verscheure, 2018). If this assumption is violated, our results would be a rather optimistic view (from a goose' perspective) as consequences for migration and fitness will likely be much more severe if changes are unexpected (Klaassen et al., 2006). Third, there might be considerable variability in shooting intensity at smaller scales. For instance, perceived and experienced risks may vary with the physical landscape (e.g. hilly terrain providing more cover than plains), with position within a group (e.g. individuals at the fringes being more vigilant while centre individuals enjoy undisturbed foraging), or with time of the day depending on the regulations that may vary between regions.

\section{4 | Management implications}

Our scenarios have shown that shooting can have counterintuitive effects that increase rather than alleviate agricultural damage as compensation behaviours may make management measures inefficient or futile. Predictions of expected agricultural damage varied substantially between our scenarios: Considering a digestive efficiency of $54 \%$ and an energy content of $1 \mathrm{~g}$ dry matter grass of 17.8 kJ (Chudzińska, Nabe-Nielsen, Nolet, \& Madsen, 2016), increasing shooting intensity in NL increased the average cumulative per capita consumption in NL from c. $4.8 \mathrm{~kg}$ dry matter to 
$6.1 \mathrm{~kg}$; increasing shooting/hunting intensity in Nenetskii oblast increased consumption in NL even more to $7.5 \mathrm{~kg}$ dry matter. These are increases of $27 \%-61 \%$, which may result in substantial economic losses even if only parts of the overall population are affected.

Furthermore, our results have shown that the consequences of management measures may differ between locations and management at one location influences the timing and intensity of how other locations are used. Although we have only investigated the consequences of shooting/hunting, other management methods, for example, creation of alternative feeding areas ("sacrificial land"), subsidies and/or compensation payments to farmers, and scaring (e.g. Fox et al., 2017; Jensen et al., 2008; Simonsen, Madsen, Tombre, \& Nabe-Nielsen, 2016; Simonsen, Tombre, \& Madsen, 2017) could be evaluated similarly and thereby assist in the identification of a management regime that minimizes conflicts with agriculture (or other human activities) while still maintaining migratory populations. Such plans are not only urgently required for our study species but for many growing waterfowl populations. For instance, a first adaptive management plan was adopted for pink-footed geese (Anser brachrhynchus) under auspices of AEWA in 2012 (Madsen et al., 2017), which involved harvest by shooting in Norway and Denmark, and complete protection in Belgium and the Netherlands. Similar international species management plans are implemented or are under preparation for other migratory goose species (taiga bean goose (Anser fabalis), greylag goose (Anser anser) and barnacle goose (Branta leucopsis)), with white-fronted goose likely being the next. Experiences with developing such plans have shown that their success depends on two salient points: (1) international agreements can be made among several states that share a migratory population, even when shooting cultures are drastically different; and (2) that any management should be adaptive. A behavioural state-dependent model such as ours can greatly assist in the development of management plans by assessing the flyway implications and efficacy of local and regional management action and scrutinizing their capacity to reduce agricultural conflicts. Ideally, a future theoretical approach to evaluating specific management measures would combine a flyway-scale model with a model that explores small-scale movements and redistributions within each site, for example, using a spatially explicit, individual-based model (Chudzińska, van Beest, Madsen, \& Nabe-Nielsen, 2015).

\section{ACKNOWLEDGEMENTS}

This study was part of the project "Towards efficient and internationally responsible management of the Dutch population of Whitefronted geese (Anser albifrons)"-initiated and financially supported by Faunafonds, carried out by Radboud Universiteit Nijmegen, Sovon and NIOO-KNAW. We thank Sabrina van der Kraats for contributing to model parameterization, Katharina Both for designing Figure 1, and two reviewers for constructive comments.

\section{CONFLICT OF INTEREST}

The authors declare no conflict of interest.

\section{AUTHORS' CONTRIBUTIONS}

S.B. and B.A.N. initiated, supervised and coordinated the project, R.J.F.M.E. calibrated the model and ran initial scenarios; S.L. ran the final scenarios and prepared the figures, M.S. calculated spring phenology across Eurasia that underlie the definition of regions, S.B. wrote the manuscript with feedback and input from all authors, and all authors gave final approval of the publication.

\section{DATA ACCESSIBILITY}

Code and parameter values for the migration model are available via Zenodo. https://doi.org/10.5281/zenodo.1197504 (Bauer, Lisovski, Eikelenboom-Kil, Shariati, \& Nolet, 2018).

\section{ORCID}

Silke Bauer (iD http://orcid.org/0000-0002-0844-164X

Simeon Lisovski (iD) http://orcid.org/0000-0002-6399-0035

Bart A. Nolet iD http://orcid.org/0000-0002-7437-4879

\section{REFERENCES}

Bauer, S., Ens, B. J., \& Klaassen, M. (2010). Many routes lead to Rome: Potential causes for the multi-route migration system of Red Knots, Calidris canutus islandica. Ecology, 91, 1822-1831. https://doi. org/10.1890/09-1281.1

Bauer, S., \& Hoye, B. J. (2014). Migratory animals couple biodiversity and ecosystem functioning worldwide. Science, 344, 1242552. https:// doi.org/10.1126/science.1242552

Bauer, S., Lisovski, S., Eikelenboom-Kil, R. J. F. M., Shariati, M., \& Nolet, B. A. (2018). Programming code: Behaviour-based migration model for assessing consequences of shooting geese along flyways, Zenodo Digital Repository, https:// doi.org/10.5281/zenodo.1197571

Bauer, S., Van Dinther, M., Høgda, K.-A., Klaassen, M., \& Madsen, J. (2008). The consequences of climate-driven stop-over sites changes on migration schedules and fitness of Arctic geese. Journal of Animal Ecology, 77, 654-660. https://doi. org/10.1111/j.1365-2656.2008.01381.x

Baveco, J. M., Kuipers, H., \& Nolet, B. A. (2011). A large-scale multispecies spatial depletion model for overwintering waterfowl. Ecological Modelling, 222, 3773-3784. https://doi.org/10.1016/j. ecolmodel.2011.09.012

Béchet, A., Giroux, J. F., \& Gauthier, G. (2004). The effects of disturbance on behaviour, habitat use and energy of spring staging snow geese. Journal of Applied Ecology, 41, 689-700. https://doi. org/10.1111/j.0021-8901.2004.00928.x

Bêty, J., Giroux, J. F., \& Gauthier, G. (2004). Individual variation in timing of migration: Causes and reproductive consequences in greater snow geese (Anser caerulescens atlanticus). Behavioral Ecology and Sociobiology, 57, 1. https://doi.org/10.1007/s00265-004-0840-3

Chudzińska, M. E., Nabe-Nielsen, J., Nolet, B. A., \& Madsen, J. (2016). Foraging behaviour and fuel accumulation of capital breeders during spring migration as derived from a combination of satellite- and ground-based observations. Journal of Avian Biology, 47, 563-574. https://doi.org/10.1111/jav.00899

Chudzińska, M. E., van Beest, F. M., Madsen, J., \& Nabe-Nielsen, J. (2015). Using habitat selection theories to predict the spatiotemporal 
distribution of migratory birds during stopover - A case study of pinkfooted geese Anser brachyrhynchus. Oikos, 124, 851-860. https://doi. org/10.1111/oik.01881

Clausen, K. K., Madsen, J., Cottaar, F., Kuijken, E., \& Verscheure, C. (2018). Highly dynamic wintering strategies in migratory geese: Coping with environmental change. Global Change Biology, 1-11, https://doi.org/10.1111/gcb.14061

Fox, A. D., Ebbinge, B. S., Mitchell, C., Heinicke, T., Aarvak, T., Colhoun, K., ... Van Der Jeugd, H. (2010). Current estimates of goose population sizes in western Europe, a gap analysis and an assessment of trends. Ornis Svecica, 20, 115-127.

Fox, A. D., Elmberg, J., Tombre, I. M., \& Hessel, R. (2017). Agriculture and herbivorous waterfowl: A review of the scientific basis for improved management. Biological Reviews, 92, 854-877. https://doi. org/10.1111/brv.12258

Fox, A. D., Glahder, C. M., \& Walsh, A. J. (2003). Spring migration routes and timing of Greenland white-fronted geese - Results from satellite telemetry. Oikos, 103, 415-425. https://doi. org/10.1034/j.1600-0706.2003.12114.x

Guillemain, M., Elmberg, J., Arzel, C., Johnson, A. R., \& Simon, G. (2008). The income-capital breeding dichotomy revisited: Late winter body condition is related to breeding success in an income breeder. Ibis, 150, 172-176.

Hessen, D. O., Tombre, I. M., van Geest, G., \& Alfsnes, K. (2017). Global change and ecosystem connectivity: How geese link fields of central Europe to eutrophication of Arctic freshwaters. Ambio, 46, 40-47. https://doi.org/10.1007/s13280-016-0802-9

Jensen, R. A., Wisz, M. S., \& Madsen, J. (2008). Prioritizing refuge sites for migratory geese to alleviate conflicts with agriculture. Biological Conservation, 141, 1806-1818. https://doi.org/10.1016/j. biocon.2008.04.027

Jongejans, E., Nolet, B. A., Schekkerman, H., Koffijberg, K., \& de Kroon, H. (2015). Naar Een Effectief En Internationaal Verantwoord Beheer van de in Nederland Overwinterende Populatie Kolganzen. Sovon-rapport 2014/56, CAPS-rapport 2014/02. Nijmegen: Sovon Vogelonderzoek Nederland.

Jonker, R. M., Eichhorn, G., van Langevelde, F., \& Bauer, S. (2010). Predation danger can explain changes in timing of migration: The case of the Barnacle goose. PLoS ONE, 5, 4-11.

Juillet, C., Choquet, R., Gauthier, G., Lefebvre, J., \& Pradel, R. (2012). Carry-over effects of spring hunt and climate on recruitment to the natal colony in a migratory species. Journal of Applied Ecology, 49, 1237-1246. https://doi.org/10.1111/j.1365-2664.2012.02199.x

Klaassen, M., Bauer, S., Madsen, J., \& Possingham, H. (2008). Optimal management of a goose flyway: Migrant management at minimum cost. Journal of Applied Ecology, 45, 1446-1452. https://doi. org/10.1111/j.1365-2664.2008.01532.x

Klaassen, M., Bauer, S., Madsen, J., \& Tombre, I. (2006). Modelling behavioural and fitness consequences of disturbance for geese along their spring flyway. Journal of Applied Ecology, 43, 92-100.

Koons, D. N., Rockwell, R. F., \& Aubry, L. M. (2014). Effects of exploitation on an overabundant species: The lesser snow goose predicament. Journal of Animal Ecology, 83, 365-374. https://doi. org/10.1111/1365-2656.12133

Kwak, R., Van der Jeugd, H. P., \& Ebbinge, B. S. (2008). The new Dutch policy to accommodate wintering waterfowl. Vogelwelt, 129, 134-140.

Lefebvre, J., Gauthier, G., Giroux, J.-F., Reed, A., Reed, E. T., \& Bélanger, L. (2017). The greater snow goose Anser caerulescens atlanticus: Managing an overabundant population. Ambio, 46, 262-274. https:// doi.org/10.1007/s13280-016-0887-1

Lehikoinen, A., Jaatinen, K., Vähätalo, A. V., Clausen, P., Crowe, O., Deceuninck, B., ... Fox, A. D. (2013). Rapid climate driven shifts in wintering distributions of three common waterbird species. Global Change Biology, 19, 2071-2081. https://doi.org/10.1111/gcb.12200
MacMillan, D. C., \& Leader-Williams, N. (2008). When successful conservation breeds conflict: An economic perspective on wild goose management. Bird Conservation International, 18, 200-210.

Madsen, J., Frederiksen, M., \& Ganter, B. (2002). Trends in annual and seasonal survival of pink-footed geese Anser brachyrhynchus. Ibis, 144, 218-226. https://doi.org/10.1046/j.1474-919X.2002.00045.x

Madsen, J., \& Klaassen, M. (2006). Assessing body condition and energy budget components by scoring abdominal profiles in free-ranging pink-footed geese Anser brachyrhynchus. Journal of Avian Biology, 37, 283-287. https://doi.org/10.1111/j.2006.0908-8857.03555.x

Madsen, J., Tamstorf, M., Klaassen, M., Eide, N., Glahder, C., Rigét, N., ... Cottaar, F. (2007). Effects of snow cover on the timing and success of reproduction in high-Arctic pink-footed geese Anser brachyrhynchus. Polar Biology, 30, 1363-1372. https://doi.org/10.1007/ s00300-007-0296-9

Madsen, J., Williams, J. H., Johnson, F. A., Tombre, I. M., Dereliev, S., \& Kuijken, E. (2017). Implementation of the first adaptive management plan for a European migratory waterbird population: The case of the Svalbard pink-footed goose Anser brachyrhynchus. Ambio, 46, 275289. https://doi.org/10.1007/s13280-016-0888-0

Menu, S., Gauthier, G., \& Reed, A. (2002). Changes in survival rates and population dynamics of greater snow geese over a 30-year period: Implications for hunting regulations. Journal of Applied Ecology, 39, 91-102. https://doi.org/10.1046/j.1365-2664.2002.00692.x

Mooij, J. H., Faragó, S., \& Kirby, J. S. (1999). White-fronted Goose Anser albifrons albifrons Goose populations of the Western Palearctic. A review of status and distribution. In J. Madsen, G. Cracknell, \& A. D. Fox (Eds.), Goose populations of the Western Palaearctic (pp. 94-128). Wageningen, The Netherlands: National Environmental Research Institute, Denmark and Wetlands International.

Morris, W. F., Pfister, C. A., Tuljapurkar, S., Haridas, C. V., Boggs, C. L., Boyce, M. S., ... Menges, E. S. (2008). Longevity can buffer plant and animal populations against changing climatic variability. Ecology, 89, 19-25. https://doi.org/10.1890/07-0774.1

Morrissette, M., Bêty, J., Gauthier, G., Reed, A., \& Lefebvre, J. (2010). Climate, trophic interactions, density dependence and carry-over effects on the population productivity of a migratory Arctic herbivorous bird. Oikos, 119, 1181-1191. https://doi.org/10.1111/j.1600-0706.2009.18079.x

Nolet, B. A., Kölzsch, A., Elderenbosch, M., \& van Noordwijk, A. J. (2016). Scaring waterfowl as a management tool: How much more do geese forage after disturbance? Journal of Applied Ecology, 53, 1413-1421. https://doi.org/10.1111/1365-2664.12698

Nuijten, R. J. M., Kölzsch, A., van Gils, J. A., Hoye, B. J., Oosterbeek, K., de Vries, P. P., ... Nolet, B. A. (2014). The exception to the rule: Retreating ice front makes Bewick's swans Cygnus columbianus bewickii migrate slower in spring than in autumn. Journal of Avian Biology, 45, 113-122. https://doi.org/10.1111/j.1600-048X.2013.00287.x

Pomeroy, A. C., Butler, R. W., \& Ydenberg, R. C. (2006). Experimental evidence that migrants adjust usage at a stopover site to trade off food and danger. Behavioral Ecology, 17, 1041-1045. https://doi. org/10.1093/beheco/arl043

Ramo, C., Amat, J. A., Nilsson, L., Schricke, V., Rodríguez-Alonso, M., Gómez-Crespo, E., ... Green, A. J. (2015). Latitudinal-related variation in wintering population trends of greylag geese (Anser anser) along the Atlantic flyway: A response to climate change?. PLoS ONE, 10, e0140181. https://doi.org/10.1371/journal.pone.0140181

Riddington, R., Hassall, M., Lane, S. J., Turner, P. A., \& Walters, R. (1996). The impact of disturbance on the behaviour and energy budgets of Brent Geese Branta b. bernicla. Bird Study, 43, 269-279. https://doi. org/10.1080/00063659609461019

Simonsen, C. E., Madsen, J., Tombre, I. M., \& Nabe-Nielsen, J. (2016). Is it worthwhile scaring geese to alleviate damage to crops? - An experimental study. Journal of Applied Ecology, 53, 916-924. https://doi. org/10.1111/1365-2664.12604 
Simonsen, C. E., Tombre, I. M., \& Madsen, J. (2017). Scaring as a tool to alleviate crop damage by geese: Revealing differences between farmers' perceptions and the scale of the problem. Ambio, 46, 319-327. https://doi.org/10.1007/s13280-016-0891-5

Stephens, P. A., Boyd, I. L., McNamara, J. M., \& Houston, A. I. (2009). Capita breeding and income breeding: Their meaning, measurement, and worth. Ecology, 90, 2057-2067. https://doi.org/10.1890/08-1369.1

Stocker, T. F., Qin, D., Plattner, G. K., Tignor, M., Allen, S. K., Boschung, J., ... Midgley, P. M. (2013). IPCC, 2013: Climate change 2013: The physical science basis. In Contribution of Working Group I to the Fifth Assessment Report of the Intergovernmental Panel on Climate Change (1535 pp).

Tombre, I. M., Eythórsson, E., Madsen, J., Madsen, J., \& Piersma, T. (2013). Towards a solution to the goose-agriculture conflict in North Norway, 1988-2012: The interplay between policy, stakeholder influence and goose population dynamics. PLoS ONE, 8, e71912. https://doi.org/10.1371/journal.pone.0071912

van Wijk, R. E., Kölzsch, A., Kruckenberg, H., Ebbinge, B. S., Müskens, G. J. D. M., \& Nolet, B. A. (2012). Individually tracked geese follow peaks of temperature acceleration during spring migration. Oikos, 121, 655-664. https://doi.org/10.1111/j.1600-0706.2011. 20083. $x$

Weber, T. P., Ens, B. J., \& Houston, A. I. (1998). Optimal avian migration: A dynamic model of fuel stores and site use. Evolutionary Ecology, 12, 377-401. https://doi.org/10.1023/A:1006560420310
Witter, M. S., \& Cuthill, I. C. (1993). The ecological costs of avian fat storage. Philosophical Transactions of the Royal Society of London B: Biological Sciences, 340, 73-92. https://doi.org/10.1098/ rstb.1993.0050

Ydenberg, R. C., Butler, R. W., Lank, D. B., Smith, B. D., \& Ireland, J. (2004). Western Sandpipers have altered migration tactics as Peregrine Falcon populations have recovered. Proceedings of the Royal Society $B$ : Biological Sciences, 271, 1263.

\section{SUPPORTING INFORMATION}

Additional Supporting Information may be found online in the supporting information tab for this article.

How to cite this article: Bauer S, Lisovski S, Eikelenboom-Kil RJFM, Shariati M, Nolet BA. Shooting may aggravate rather than alleviate conflicts between migratory geese and agriculture. J Appl Ecol. 2018;55:2653-2662. https://doi. org/10.1111/1365-2664.13152 